\title{
Carrot alternative oxidase gene AOX2a demonstrates allelic and genotypic polymorphisms in intron 3
}

\author{
Hélia Guerra Cardoso ${ }^{a}$, Maria Doroteia Campos ${ }^{a}$, Ana Rita Costa ${ }^{a}$, Maria Catarina Campos ${ }^{\text {a }}$, Thomas \\ Nothnagel ${ }^{\mathrm{b}}$ and Birgit Arnholdt-Schmitt ${ }^{\mathrm{a},{ }^{\star}}$
}

\author{
${ }^{a}$ EU Marie Curie Chair, ICAAM, University of Évora, Apartado 94, 7002-554 Évora, Portugal \\ b Julius Kühn-Institut, Federal Research Centre for Cultivated Plants, Institute for Breeding Research on \\ Horticultural and Fruit Crops, Erwin-Baur-Str. 27, D-06484 Quedlinburg, Germany \\ Correspondence to * e-mail: eu_chair@uevora.pt
}

\section{ABSTRACT}

Single nucleotide polymorphisms (SNPs) and insertion-deletions (InDels) are becoming important genetic markers for major crop species. In this study, we focus on variations at genomic level of the Daucus carota L. $A O X 2 a$ gene. The use of gene-specific primers designed in exon regions on the boundaries of introns permitted to recognize intron length polymorphism (ILP) in intron 3 AOX2a by simple polymerase chain reaction (PCR) assays. The length of intron 3 can vary in individual carrot plants. Thus, allelic variation can be used as a tool to discriminate between single plant genotypes. Using this approach, individual plants from cv. Rotin and from diverse breeding lines and cultivars were identified that showed genetic variability by AOX2a ILPs. Repetitive patterns of intron length variation have been observed which allows grouping of genotypes. Polymorphic and identical PCR fragments revealed underlying high levels of sequence polymorphism. Variability was due to InDel events and intron single nucleotide polymorphisms (ISNPs), with a repetitive deletion in intron 3 affecting a putative pre-miRNA site. The results suggest that high AOX2a gene diversity in $D$. carota can be explored for the development of functional markers related to agronomic traits.

Received 9 June 2009; revised 24 September 2009

DOI: $10.1111 / \mathrm{j} .1399-3054.2009 .01299 . x$

Full article available: http://www3.interscience.wiley.com/journal/122618552/abstract 